\title{
Conversion of Solar Energy to Fuels by Inorganic Heterogeneous Systems
}

\author{
Kimfung LI, David MARTIN, Junwang TANG* \\ Department of Chemical Engineering, University College London, Torrington Place, London, WC1E 7JE, UK
}

\begin{abstract}
Over the last several years, the need to find clean and renewable energy sources has increased rapidly because current fossil fuels will not only eventually be depleted, but their continuous combustion leads to a dramatic increase in the carbon dioxide amount in atmosphere. Utilisation of the Sun's radiation can provide a solution to both problems. Hydrogen fuel can be generated by using solar energy to split water, and liquid fuels can be produced via direct $\mathrm{CO}_{2}$ photoreduction. This would create an essentially free carbon or at least carbon neutral energy cycle. In this tutorial review, the current progress in fuels' generation directly driven by solar energy is summarised. Fundamental mechanisms are discussed with suggestions for future research.
\end{abstract}

Key words: solar energy; photocatalysis; carbon dioxide conversion; water splitting

CLC number: O643 Document code: A

Received 30 October 2010. Accepted 5 January 2011.

*Corresponding author. Tel: +44-20-7679-7393; E-mail: Junwang.tang@ucl.ac.uk

This work was supported by the Engineering and Physical Sciences Research Council (EPSRC).

English edition available online at Elsevier ScienceDirect (http://www.sciencedirect.com/science/journal/18722067).

The increasing demand for global energy has drawn much attention to the field of energy development. It is predicted that the annual amount of energy requirement will double in the next fifty years from $13.5 \mathrm{TW} /$ year in 2001 to $27 \mathrm{TW} /$ year in 2050 [1,2]. At present, the main energy output comes from hydrocarbon fuels, and only $20 \%$ comes from other energy sources such as tidal power, nuclear energy, biomass, photovoltaics, etc. Hydrocarbon fuels have many advantages over the other types of fuels, including easy storage and transportation, availability and a high volumetric energy density $\left(33 \mathrm{GJ} / \mathrm{m}^{3}\right)$ [3]. The total amount of global hydrocarbon fuel available is limited and the large amounts of $\mathrm{CO}_{2}$ emitted from burning hydrocarbon fuels are a significant drawback against their application. Moreover, safety and health issues behind the storage of hydrocarbon fuels are often ignored. The oil spill in the Gulf of Mexico has caused an enormous impact to the marine ecosystem, which has greatly increased the awareness and need for alternative clean energy. Taking into account all these factors, the development of new sources of renewable and clean energy to replace fossil fuels has become one of the most important topics for humans today.

Sunlight is the most abundant renewable energy source in the world. The energy hitting the Earth's surface is about $100000 \mathrm{TW} /$ year [4]. In addition, solar energy is clean, non-monopolized, and environmentally friendly. The only drawback is its intermittent irradiation. Therefore, the ability to capture, convert, and store solar energy for later use is the primary goal for researchers in the field today. Nature has shown us how to utilise sunlight and learning from it will teach us to develop a sustainable energy source. In natural photosynthesis, plants oxidize water in the PSII reaction centre leading to the formation of $\mathrm{O}_{2}$ and production of reducing equivalents. These are further used in the Calvin cycle in the reduction of $\mathrm{CO}_{2}$. Following a similar mechanism, an artificial system can be designed not only to oxidize the water in a light driven process to produce $\mathrm{O}_{2}$ but also to drive the reduction of protons to yield hydrogen. Hydrogen has the highest energy density of fuels by weight. It has a maximum efficiency of $38 \%$ when used in an Otto cycle internal combustion engine, which is $8 \%$ higher than a gasoline internal combustion engine. Water is the only combustion product of hydrogen driven system. Due to these advantages, hydrogen generation by a sunlight driven water spitting process has been widely investigated.

Besides the concern of the limited amount of hydrocarbon fuels reserve, the impact of burning fossil fuels is huge. Researches based on many climate simulations suggest that at the current increase rate of atmospheric $\mathrm{CO}_{2}$ concentration, the average global temperature will go up about $6{ }^{\circ} \mathrm{C}$ before the end of this century. $6{ }^{\circ} \mathrm{C}$ is sufficient to switch Earth's climate from glacial conditions to an ice-free Antarctica $[5,6]$. While discussions have begun on means to reduce $\mathrm{CO}_{2}$ emissions, it is apparent that the atmospheric $\mathrm{CO}_{2}$ concentration will continue to increase due to hydrocarbon consumption. Approximately 1 billion barrels of oil 
are consumed to supply the world energy requirement every 12 days, which represents nearly 1 trillion pounds of $\mathrm{CO}_{2}$ released to the atmosphere. In response to this, there are several strategies developed to reduce $\mathrm{CO}_{2}$ levels. Reduction of $\mathrm{CO}_{2}$ levels can be achieved by carbon capture and storage (CCS) in which $\mathrm{CO}_{2}$ collected from its emission sources would be buried under the Earth [7]. However, the compression and burial of $\mathrm{CO}_{2}$ require extra energy, generating more $\mathrm{CO}_{2}$. In addition to the extra energy requirement for storing $\mathrm{CO}_{2}$, burying $\mathrm{CO}_{2}$ also has the risk of leakage, and in 1986 the eruption of naturally sequestrated $\mathrm{CO}_{2}$ asphyxiated 1700 people in Cameroon [8].

Recycling $\mathrm{CO}_{2}$ and converting it into a high-energy fuel is an advanced solution. However, $\mathrm{CO}_{2}$ is the thermodynamic final product of combustion, thus it is very stable and $\mathrm{CO}_{2}$ conversion requires huge energy input. $\mathrm{CO}_{2}$ can be converted by biomass production process, thermochemical, electrochemical, and photochemical methods. Biomass to fuel is a viable approach for carbon recycling, and involves $\mathrm{CO}_{2}$ absorption by plants during photosynthesis [9,10]. However, it is well known that the whole process is very time consuming and characterized by an extremely low efficiency. Unlike photoreduction of $\mathrm{CO}_{2}$, thermal or electrochemical process requires very high temperatures or a strong external voltage bias to provide energy to drive the reaction, which lowers the efficiency of the device and limits its deployment. Photocatalysis can reduce $\mathrm{CO}_{2}$ to produce hydrocarbons in a similar way to the Calvin cycle in natural photosynthesis. This is also another approach to convert and store solar energy. The following equations ((1) -(8)) illustrate solar fuel generation pathways, including solar $\mathrm{H}_{2}$ production and conversion of $\mathrm{CO}_{2}$ to potential fuels driven by photocatalysis [11].

Solar hydrogen: $\quad$ Chemical potential (eV vs. NHE)

$2 \mathrm{H}_{2} \mathrm{O}+4 \mathrm{~h}^{+} \rightarrow \mathrm{O}_{2}+4 \mathrm{H}^{+}$
$2 \mathrm{H}^{+}+2 \mathrm{e}^{-} \rightarrow \mathrm{H}_{2}$

$\mathrm{CO}_{2}$ conversion:

$\mathrm{CO}_{2}+\mathrm{e}^{-} \rightarrow \mathrm{CO}_{2}^{-} \quad-1.49$

$\mathrm{CO}_{2}+2 \mathrm{H}^{+}+2 \mathrm{e}^{-} \rightarrow \mathrm{HCOOH} \quad-0.19$

$\mathrm{CO}_{2}+2 \mathrm{H}^{+}+2 \mathrm{e}^{-} \rightarrow \mathrm{CO}+\mathrm{H}_{2} \mathrm{O} \quad-0.19$

$\mathrm{CO}_{2}+4 \mathrm{H}^{+}+4 \mathrm{e}^{-} \rightarrow \mathrm{HCHO}+\mathrm{H}_{2} \mathrm{O} \quad-0.06$

$\mathrm{CO}_{2}+6 \mathrm{H}^{+}+6 \mathrm{e}^{-} \rightarrow \mathrm{CH}_{3} \mathrm{OH}+\mathrm{H}_{2} \mathrm{O}+0.03$

$\mathrm{CO}_{2}+8 \mathrm{H}^{+}+8 \mathrm{e}^{-} \rightarrow \mathrm{CH}_{4}+\mathrm{H}_{2} \mathrm{O}$

$+0.18$

This short review focuses on solar hydrogen production from water splitting and $\mathrm{CO}_{2}$ conversion by inorganic heterogeneous systems and the use of semiconductor photocatalysts. The principles of how inorganic photocatalysts operate under sunlight are first described, and then there is an analysis of the up-to-date research situation including the active materials for both reaction pathways and some important factors influencing conversion efficiency. Finally, mechanistic work that is being carried out to guide the de- sign of the next generation of materials will be discussed.

Photocatalytic fuel production has been widely studied and is a fast moving field. A number of excellent review articles have been published in recent years [11-15]. Therefore, we concentrate on a limited number of representative materials in this tutorial review. We do not consider in detail the use of photocatalytic films as photoanodes and photocathodes and homogeneous systems.

\section{Fundamental Knowledge}

Water splitting and $\mathrm{CO}_{2}$ conversion processes share the same energy scheme (Fig. 1). When light is incident on the semiconductor, electrons located in the valence band (VB) in the semiconductor can be excited by light having energy greater than the band gap of semiconductor, the energy difference between the top of the filled valence band and the bottom of the empty conduction band (CB), resulting in the electrons being promoted from the $\mathrm{VB}$ to the $\mathrm{CB}$, simultaneously leaving positively charged holes in the VB. The pair can, if recombination does not happen as fast as separation and transportation, travel to the surface of semiconductor and split water to produce oxygen and hydrogen, or reduce $\mathrm{CO}_{2}$ to yield hydrocarbons (e.g. alcohols)

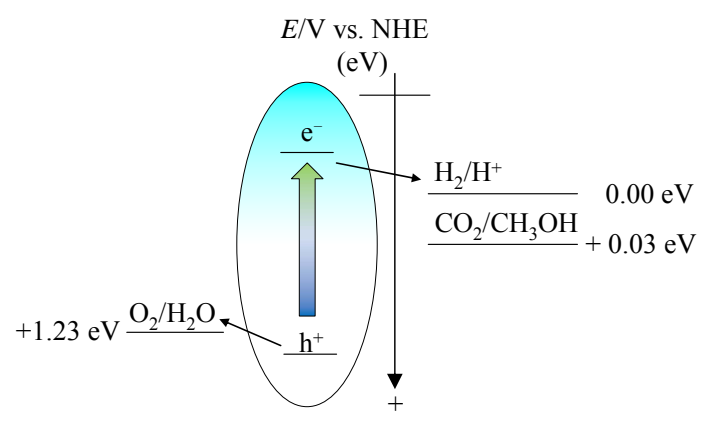

Fig. 1. Systematic diagram of the fundamental mechanism of heterogeneous photocatalysis.

In order to reduce $\mathrm{CO}_{2}$ to fuel, e.g. methanol, or produce hydrogen from water, the electrons in the $\mathrm{CB}$ must have a potential that is more negative than the redox potential of $\mathrm{CO}_{2} / \mathrm{CH}_{3} \mathrm{OH}(\sim 0.03 \mathrm{eV}$ vs. $\mathrm{NHE})$ or $\mathrm{H}^{+} / \mathrm{H}_{2}(0 \mathrm{eV}$ vs. NHE) to provide the driving force for the reaction. On the other hand, water oxidation occurs when the hole potential is more positive than the redox potential of $\mathrm{O}_{2} / \mathrm{H}_{2} \mathrm{O}(+1.23 \mathrm{eV}$ vs. NHE). On this basis a minimum band gap energy of $1.23 \sim 1.27 \mathrm{eV}$ is required. In practice, the minimum practical energy required to drive photocatalytic conversion is much higher due to energy losses associated with the overpotentials required for the two chemical reactions and driving force for charge carrier transportation. Ultraviolet light $(<$ $400 \mathrm{~nm}$ ) only contributes less than $4 \%$ to sunlight spectrum, while $43 \%$ of light is in visible region $(400 \sim 750 \mathrm{~nm})$. 


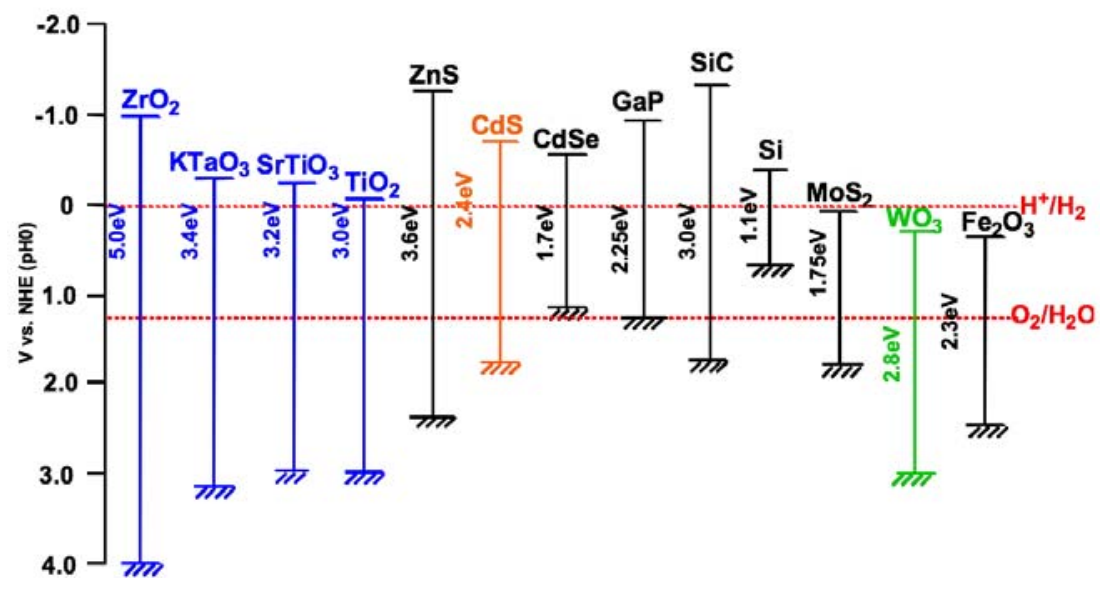

Fig. 2. Band levels of simple semiconductors. Reproduced from Ref. [12].

Therefore the development of a photocatalyst with activity from the UV through to visible wavelengths $(\sim 750 \mathrm{~nm})$ and with a VB and $\mathrm{CB}$ that straddle the reaction potentials is one of key goals in obtaining optimum solar to fuel efficiency. The band gaps of some simple semiconductors have been measured and are shown in Fig. 2.

The reaction process on semiconductor photocatalysts is often considered as comprising three steps: (1) charge carrier (electron/hole) generation following absorption of a photon of suitable energy, (2) charge carrier separation and transportation, (3) chemical reaction between surface species and the charge carriers. The first two steps are photophysical and the final step is a chemical process. A photocatalytic reaction is therefore a complicated combination of photophysical and photochemical processes. Besides enhancing the ability of visible light harvesting (step (1)), there is equal importance in the development of a fast charge separation system (step (2)) and altering material morphology and surface modification to increase the reaction rate (step (3)).

There have been numerous examples in the literature of semiconductor materials that are able to evolve either hydrogen or oxygen from water in the presence of a suitable charge carrier scavenger (e.g. to have $\mathrm{H}_{2}$ production, a hole scavenger is employed). However, the majority of these are unable to produce both oxygen and hydrogen simultaneously in stoichiometric ratio in the absence of sacrificial reagents. This demonstrates that although the correct positioning and energy of the band gap are prerequisite, it is not the sole factor in determining the heterogeneous photocatalytic activity. Other factors such as kinetic competition through charge carrier recombination, which may occur at a faster rate than the required surface reductive and oxidative chemistry, can be the dominant factor in determining reactivity towards the water splitting reaction.

In contrast to water splitting, only few examples have been reported for $\mathrm{CO}_{2}$ photoconversion. Although $\mathrm{CO}_{2}$ photoconversion has a similar mechanism, it requires 2-8 electrons to reduce $\mathrm{CO}_{2}$ into the desired product. In other words, more free electrons are required in the photocatalyst. The difficulty for building up a high concentration of free electrons in the semiconductor is that the recombination rate would dramatically increase too.

\section{Material development}

\subsection{Solar hydrogen generation}

In 1972, Fujishima and Honda [16] found that $\mathrm{TiO}_{2}$ can produce a photocurrent in an electrochemical cell when they used $\mathrm{Pt}$ as the counter-electrode and applied an electrical bias. Extensive research has been put into this field after this original benchmark was set. $\mathrm{TiO}_{2}$ has been continually investigated by various methods, including doping with different elements, changing the particle morphology and applying different cocatalysts. In 1985, Yamaguti and Sato [17] found that $\mathrm{Rh}$ and $\mathrm{NaOH}$ co-loaded $\mathrm{TiO}_{2}$ had an enormous increase in activity compared to $\mathrm{TiO}_{2}$ itself in photocatalytic water splitting process. Selli et al. [18] reported electron transportation from $\mathrm{TiO}_{2}$ photoanode to the $\mathrm{Pt}$ cathode was enhanced by a $\mathrm{pH}$ difference between the two under an external bias. Duonghong et al. [19] reported a $\mathrm{TiO}_{2}$ colloid loaded with $\mathrm{Pt}$ and $\mathrm{RuO}_{2}$ led to an increased quantum yield, and obtained both hydrogen and oxygen under UV illumination. $\mathrm{H}_{2}$ generation rate reached $2.8 \mathrm{ml} / \mathrm{h}$, which was much higher than the $1 \mathrm{ml} / \mathrm{h}$ without $\mathrm{RuO}_{2}$ [20]. $\mathrm{O}_{2}$ production was not detected at the beginning of the experiment, which was assumed due to its strong adsorption on the catalyst in the initial period. Instead of using anatase $\mathrm{TiO}_{2}, \mathrm{Fu}$ et al. [21] studied bicrystalline titania $\left(\mathrm{TiO}_{2}(\mathrm{~B})\right)$. They synthesised and investigated a heteropoly blue sensitizer and $\mathrm{Pt}$ loaded $\mathrm{TiO}_{2}(\mathrm{~B})$ nanoribbon for water decompo- 
sition for hydrogen evolution. Their result showed that a mixture of $\mathrm{TiO}_{2}(\mathrm{~B})$ and anatase gave the maximum quantum yield (quantum yield $(\mathrm{QY})=8.11 \%$ ), suggesting that interfacial charge separation improved the efficiency. In another report by this group, the solvent effect of water splitting was investigated. The hydrogen production rate was found to be increased in the presence of monochloroacetic acid and dichloroacetic acid with Pt/P25 as the photocatalyst [22]. A large number of investigations had made efforts to improve this cheap, stable, and non-toxic material. Unfortunately $\mathrm{TiO}_{2}$ is still limited by its large band gap, which makes the photocatalyst only responsive to the UV or near UV region of the solar spectrum. Despite this, scientists have pioneered a range of UV responsive photocatalytic materials.

Domen's group paid particular attention to $\mathrm{SrTiO}_{3}$ - a perovskite structured material [23-28]. They examined the use of a $\mathrm{NiO}$ cocatalyst mounted on $\mathrm{SrTiO}_{3}$ as a photocatalyst in water under UV radiation, and reported both oxygen and hydrogen production. The study showed the $\mathrm{NiO}$ cocatalyst was prepared by $\mathrm{H}_{2}$ reduction and subsequent $\mathrm{O}_{2}$ oxidation on $\mathrm{NiO}$ to form a $\mathrm{Ni} / \mathrm{NiO}_{x}$ double layer (termed $\mathrm{NiO}$ ). Kim et al. [29] studied another important titanate, $\mathrm{La}_{2} \mathrm{Ti}_{2} \mathrm{O}_{7}$, which is a layered structure material consisting of four $\mathrm{TiO}_{6}$ unit slabs separated by $\mathrm{La}^{3+}$ ions layers. They reported that when $\mathrm{La}_{2} \mathrm{Ti}_{2} \mathrm{O}_{7}$ splits water, $\mathrm{H}_{2}$, and $\mathrm{O}_{2}$ were produced in large amounts (QY up to $12 \%$ ) in the presence of a $\mathrm{NiO}$ cocatalyst under $\mathrm{UV}$. $\mathrm{ZrO}_{2}$ has a very large band gap $(5.0-5.7 \mathrm{~V})$, but can split water without a cocatalyst under UV illumination [30]. Sayama and Arakawa [31] reported the use of $\mathrm{ZrO}_{2}$ with added alkali carbonate in water, $\mathrm{NaHCO}_{3}$, gave the highest efficiency in water splitting. It is worth noting that the addition of other common metals and metal oxides as cocatalysts to $\mathrm{ZrO}_{2}$ led to a decrease in photocatalytic activity in water splitting, which differed from other photocatalysts. This suggests that there is a large energetic barrier between the cocatalyst and semiconductor as a result of the large bandgap and position of the $\mathrm{CB}$ and VB. Jiang et al. [32] turned their attention to $\mathrm{ZrW}_{2} \mathrm{O}_{8}$ in order to overcome the problem of $\mathrm{ZrO}$ having large band gap. $\mathrm{ZrW}_{2} \mathrm{O}_{8}$ was estimated to have a band gap of about 4.0 $\mathrm{eV}$. It showed ability to decompose water to yield hydrogen or oxygen in the presence of an appropriate electron or hole scavenger under a $300 \mathrm{~W} \mathrm{Hg-Xe} \mathrm{lamp.} \mathrm{The} \mathrm{production} \mathrm{rate}$ wasn't particularly high, with $23.4 \mu \mathrm{mol} / \mathrm{h}$ of hydrogen and $9.8 \mu \mathrm{mol} / \mathrm{h}$ of oxygen [32].

Tantalates and niobates have shown high performances in photocatalytic activity for water splitting. Many researchers have studied and reported $\mathrm{MTaO}_{3}$ [33-36], $\mathrm{M}_{2} \mathrm{Ta}_{2} \mathrm{O}_{7}$ [37-39], $\mathrm{MTa}_{2} \mathrm{O}_{6}$ [40], and $\mathrm{M}_{2} \mathrm{Nb}_{2} \mathrm{O}_{7}(\mathrm{M}=$ alkaline metal or earth alkaline metal) $[38,40,41]$ gave both hydrogen and oxygen production simultaneously when reacted with water under UV illumination. Although the large band gaps of these materials limit their ability to absorb the major parts of sunlight, the facile modification of the photocatalyst by the incorporation of a suitable foreign metal into the $\mathrm{A} / \mathrm{M}$ or $\mathrm{B}$ sites in the perovskite structure $\left(\mathrm{ABO}_{3}\right)$ or tantalates/niobates allows the preparation of a different derivative photocatalyst. Kato et al. [34,35] reported NiO loaded $\mathrm{NaTaO}_{3}$ exhibited a particularly high quantum yield (QY $=$ $20 \%$ at $270 \mathrm{~nm}$ ) for both hydrogen and oxygen production. In subsequent work [36], they found that by doping Na$\mathrm{TaO}_{3} / \mathrm{NiO}$ with $2 \mathrm{~mol} \% \mathrm{La}$, the quantum yield was increased dramatically to $56 \%$. It was believed that the La ion had an effect in reducing the particle size and enhanced the material's surface area and reaction sites. $\mathrm{M}_{4} \mathrm{Nb}_{6} \mathrm{O}_{17}$, a typical layered material, was active for complete water splitting under UV light as reported by Sayama [33]. In a further study it was suggested that $\mathrm{H}_{2}$ and $\mathrm{O}_{2}$ were produced in different layers, which reduced the chance of charge recombination. Although $\mathrm{M}_{4} \mathrm{Nb}_{6} \mathrm{O}_{17}$ was able to split water without any cocatalyst, Domen reported that hydrogen production could be enhanced by suitable hole scavengers due to the ion exchange of protons [25].

Besides the transition metal photocatalysts, main group metal oxide materials have also been investigated as photocatalysts for water splitting by many researchers. Elements in groups 13 and 14, e.g. In, Sn, Sb, Ga, and Ge have been reported to be active for water splitting when mounted with appropriate cocatalysts. Sato et al. $[42,43]$ reported $\mathrm{MIn}_{2} \mathrm{O}_{4}$ $(\mathrm{M}=\mathrm{Ca}, \mathrm{Sr}$, and $\mathrm{Ba})$, which had distorted $\mathrm{InO}_{6}$ octahedra in the lattice, showed $\mathrm{H}_{2}$ and $\mathrm{O}_{2}$ production from pure water when a cocatalyst $\left(\mathrm{RuO}_{x}\right)$ was added to the materials through an impregnation method. $\mathrm{CaIn}_{2} \mathrm{O}_{4}$ exhibited the highest activity under UV light. Ye et al. [44-46] reported $\mathrm{MSnO}_{3}(\mathrm{M}=\mathrm{Ca}, \mathrm{Sr}$, and $\mathrm{Ba})$ suspended in pure water gave hydrogen and oxygen in the presence of a $\mathrm{RuO}_{2}$ cocatalyst. $\mathrm{SrSnO}_{3}$ had the highest photocatalytic activity due to a suitable band position and fast photogenerated charge carrier transfer in the proper distortion of $\mathrm{SnO}_{6}$ in $\mathrm{SrSnO}_{3}$. A study of the $\mathrm{SrSnO}_{3}$ morphology found that $\mathrm{SrSnO}_{3}$ nanorods achieved a 10 fold increase in photocatalytic activity when compared to standard particles with a similar surface area and optical density [46]. Sato et al. [47] have also found $\mathrm{M}_{2} \mathrm{Sb}_{2} \mathrm{O}_{7}$ can split water into hydrogen and oxygen in a near-stoichiometric ratio under UV radiation.

A number of non-oxide materials such as sulphides and nitrides have been recognised for their ability to split water under UV illumination. The valence bands of these materials are composed of S $3 p$ or N $2 p$ orbitals. In this category, $\mathrm{ZnS}$ has been most investigated. Yanagida et al. [48] first reported the production of hydrogen from $\mathrm{ZnS}$ under $125 \mathrm{~W}$ Hg lamp illumination using tetrahydrofuran as hole scavenger. In another experiment, $\mathrm{D}_{2} \mathrm{O}$ was used instead of water to confirm that the evolution of hydrogen was directly 
caused by photocatalytic water splitting [48]. Reber et al. [49] systematically examined $\mathrm{ZnS}$ photocatalytic activity over a range of changing conditions including electron donor, $\mathrm{pH}$ and temperature. They reported a $90 \%$ quantum yield for hydrogen production at $313 \mathrm{~nm}$ illumination of $\mathrm{ZnS}$ coated with Pt in a solution of $\mathrm{Na}_{2} \mathrm{~S}, \mathrm{H}_{3} \mathrm{PO}_{3}$, and $\mathrm{NaOH}$ [49,50]. Kobayakawa et al. [51] obtained hydrogen from $\mathrm{CuInS}_{2}$ and $\mathrm{CuIn}_{5} \mathrm{~S}_{8}$ suspended in water with a sulphite hole scavenger under UV illumination. However, all these metal sulphides or nitrides suffered from poor stability in the system, and they were easily oxidised by water.

Over $43 \%$ of sunlight is in the visible part of the spectrum, with only $4 \%$ of sunlight in UV region. In order to maximise the use of solar energy, the development of visible light driven photocatalysts is thus of the first priority. This means that the band gap of the material must be small. However, it is hard to find such a narrow band gap material with suitable $\mathrm{CB}$ and $\mathrm{VB}$ energy levels to provide the over-potentials for the redox reactions. $\mathrm{WO}_{3}$ is a well-known photocatalyst for oxygen production in water oxidation, but the conduction band position of it makes hydrogen production energetically unfavourable. Attempts at incorporating different elements have been tried to enable hydrogen production on tungsten oxide to overcome the problem. $\mathrm{AgInW}_{2} \mathrm{O}_{8}, \mathrm{AgBiW}_{2} \mathrm{O}_{8}$, and $\mathrm{Ag}_{2} \mathrm{WO}_{4}$ were said to have a higher conduction band than $\mathrm{WO}_{3}$ based on theoretical calculations, and which would allow hydrogen production. The latter material can actively produce both oxygen and hydrogen, as shown by Tang et al $[52,53]$. Kudo et al. [54-56] reported monoclinic $\mathrm{BiVO}_{4}$, an important photocatalyst commonly used in water oxidation to produce oxygen, has a maximum QY of $9 \%$ under visible light (450nm) irradiation. It was found to be heavily dependent on the preparation method, and the crystal phase sample obtained from soft chemical synthesis with the monoclinic phase exhibited a higher activity than samples from high temperature solid reactions, regardless of the surface area of the catalyst. The lower efficiency was probably due to the higher number of defect sites in the material increasing the recombination probability.

Most of the visible light driven photocatalysts for water splitting require appropriate sacrificial reagents. Only a few metal oxides have been reported active for complete water splitting. Zou et al. [57] reported Ni-doped $\mathrm{InTaO}_{4}$ can split water in absence of scavenger species. In the presence of a $\mathrm{RuO}_{2}$ or NiO cocatalyst, the stoichiometric ratio of $\mathrm{H}_{2}$ and $\mathrm{O}_{2}$ was 2:1, with a QY of $0.66 \%$ at $402 \mathrm{~nm}$. The undoped $\mathrm{NiO}-\mathrm{InTaO}_{4}$ has also been investigated and found to be less active, which was due to the replacement of $\mathrm{Ni}^{2+}$ to $\mathrm{In}^{3+}$ inducing a contraction of the lattice and the partially filled Ni $d$-orbitals reduced the band gap of the material leading to visible light absorption $(<480 \mathrm{~nm})$.
Sulfides have also great potential as visible light photocatalysts for the production of solar $\mathrm{H}_{2}$ but their application has been limited due to photo-corrosion. CdS has been the most extensively investigated due to its narrow band gap and ideal band positions for both $\mathrm{O}_{2}$ and $\mathrm{H}_{2}$ evolution (CB $-0.87 \mathrm{eV}$ and VB $1.5 \mathrm{eV}$ vs. NHE). Both the Mills group [58] and Darwent group [59,60] studied CdS for $\mathrm{H}_{2}$ production using EDTA as an electron donor. They found that with the addition of a Pt cocatalyst, CdS gave improved $\mathrm{H}_{2}$ evolution rates by a factor of 10 from aqueous EDTA. A very high activity for $\mathrm{H}_{2}$ evolution was reported for Pt-CdS in $\mathrm{Na}_{2} \mathrm{SO}_{3}$ aqueous solution (QY $=35 \%, 430 \mathrm{~nm}$ ). Recently, Yan et al. [61] improved the activity of $\mathrm{CdS}$ for $\mathrm{H}_{2}$ production in $\mathrm{Na}_{2} \mathrm{~S}$ and $\mathrm{Na}_{2} \mathrm{SO}_{3}$ solution by co-functionalizing $\mathrm{CdS}$ with Pt and PdS leading to a QY of $93 \%$ at $420 \mathrm{~nm}$. Another report from Kalyanasundaram et al. [62] have shown that $\mathrm{CdS}$ with $\mathrm{Pt}$ and $\mathrm{RuO}_{2}$ reduced the photocorrosion effect and gave an effective water splitting photocatalyst under visible light. In order to enhance the resistance to photocorrosion, electron donors such as $\mathrm{S}^{2-}, \mathrm{SO}_{3}{ }^{2-}$, are often loaded into the water solution. Various strategies have been employed to overcome such problems, e.g., encapsulation of $\mathrm{CdS}$ nanoparticles, formation of CdS composites with $\mathrm{TiO}_{2}$ and $\mathrm{ZnS}$, and doping of $\mathrm{CdS}$ by noble metals and transition metals. Domen et al. [63-68] have developed a family of nitride/oxynitride visible light-driven materials. $\mathrm{TaOH}$ has been found to be active for $\mathrm{O}_{2}$ evolution (QY $=34 \%$, $420-500 \mathrm{~nm})$ in the presence of $\mathrm{AgNO}_{3}$ as electron scavenger [64]. More recently, systems comprising solid solutions of nitride-oxide mixtures were reported [69-71], such as GaN-ZnO, typically $\mathrm{Ga}_{0.88} \mathrm{~N}_{0.88} \mathrm{Zn}_{0.12} \mathrm{O}_{0.12}$ coated with a cocatalyst $\mathrm{Rh}_{2-x} \mathrm{Cr}_{x} \mathrm{O}_{3}$, which were able to split water with a high QY under visible illumination $(\mathrm{QY}=5.9 \%, 420 \mathrm{~nm})$. In order to get this record high QY, it was essential that the $\mathrm{pH}$ was adjusted to 4.5 with $\mathrm{H}_{2} \mathrm{SO}_{4}$.

Apart from the representative materials described above, others are described in several other important review works on materials for solar $\mathrm{H}_{2}$ and/or $\mathrm{O}_{2}$ production published recently. Those interested in these materials are recommended to read these reviews $[11,12,72]$.

\subsection{Photoreduction of $\mathrm{CO}_{2}$}

While photo-assisted water splitting has been heavily researched, $\mathrm{CO}_{2}$ conversion has not yet been developed at the same rate. The reduction of $\mathrm{CO}_{2}$ is a much more challenging process compared to water splitting, as 2-8 electrons are required to reduce $\mathrm{CO}_{2}$ into potential hydrocarbon fuels. The significance of finding a suitable material that can do this is considered more important than hydrogen production, as it produces fuel and use $\mathrm{CO}_{2}$ in one step, aiding both our energy needs and preventing increased climate change. 
Reduction of $\mathrm{CO}_{2}$ by a single crystal semiconducting material in a photoelectric system was reported by Halmann [73]. It was found that in an electrochemical cell, $\mathrm{CO}_{2}$ can be reduced to give formic acid, formaldehyde, and methanol. The conditions were a single $p$-type GaP crystal as a photocathode, a carbon rod as the counter electrode, aqueous buffered electrolyte solution, and $\mathrm{CO}_{2}$ bubbled through the solution, which were irradiated by a mercury lamp. In later work, the use of $p$-type GaAs and $p$-type InP single crystals to reduce $\mathrm{CO}_{2}$ to methanol in $\mathrm{CO}_{2}$-saturated $\mathrm{Na}_{2} \mathrm{SO}_{4}$ solution under bias was reported by Canfield and Frese [74].

The results published so far showed that semiconductor nanoparticles possess higher photocatalytic performance for $\mathrm{CO}_{2}$ reduction compared to bulk material. Extremely small $\mathrm{TiO}_{2}$ particles having large band gaps showed the highest efficiency for $\mathrm{CH}_{4}$ formation [75]. Fujishima and Inoue et al. [76] first reported the photocatalytic reduction of $\mathrm{CO}_{2}$ on various semiconductor powders, including $\mathrm{GaP}, \mathrm{TiO}_{2}, \mathrm{ZnO}$, $\mathrm{CdS}, \mathrm{SiC}$, and $\mathrm{WO}_{3}$, in an aqueous suspension system with $\mathrm{CO}_{2}$ bubbling illuminated by a Xe lamp without of aid of an external bias. Overall, a small amount of formic acid, formaldehyde, methane, and methanol were produced. They suggested the conversion of $\mathrm{CO}_{2}$ to hydrocarbon products occurred by a multistep reaction pathway, and the formation selectivity of product was influenced by the conduction band position of the photocatalyst. The yield of methanol increased as the conduction band of the photocatalysts became more negative compared to the redox potential of $\mathrm{CH}_{3} \mathrm{OH} / \mathrm{H}_{2} \mathrm{CO}_{3}$. $\mathrm{WO}_{3}$ has a more positive conduction band than $\mathrm{CH}_{3} \mathrm{OH} / \mathrm{H}_{2} \mathrm{CO}_{3}$, and therefore methanol was not obtained in the process. Yahaya et al. [77] studied $\mathrm{TiO}_{2}, \mathrm{NiO}$ and $\mathrm{ZnO}$ for $\mathrm{CO}_{2}$ reduction under a $355 \mathrm{~nm}$ pulsed laser. From their result, they suggested that the reduction process of $\mathrm{CO}_{2}$ does not follow a single mechanism, and the reduction of $\mathrm{H}_{2} \mathrm{CO}_{3}$ and carbonate ions as well as other mechanisms also affect the production of methanol.

$\mathrm{TiO}_{2}$ has also drawn much interest in the $\mathrm{CO}_{2}$ photocatalytic reduction research field, due to the suitability of its band gap as well as the aforementioned non-toxic, low-cost, and stable properties. There have been numerous modifications made on $\mathrm{TiO}_{2}$. Anpo and Chiba [78] used dispersed $\mathrm{TiO}_{2}$ anchored on porous Vycor glass to reduce $\mathrm{CO}_{2}$ under UV illumination, which resulted in the production of methane, methanol, and carbon monoxide. From the direct detection of intermediate species, they proposed that methane came from the reaction between carbon radicals and atomic hydrogen. The photoreaction efficiency strongly depended on the $\mathrm{CO}_{2}$ to $\mathrm{H}_{2} \mathrm{O}$ ratio and reaction temperature.

Ichikawa and Doi [79] reduced $\mathrm{CO}_{2}$ to methane and ethylene by Nafion film with $\mathrm{TiO}_{2}$ and $\mathrm{ZnO} / \mathrm{Cu}$ coated on different sides under an external bias, with $82 \%$ of the $\mathrm{CO}_{2}$ converted, giving $44 \%$ of methane and $24 \%$ of ethylene.
Their system consisted of a perforated thin film titania and an electrocatalyst separated by a proton separator. Water flowed into the thin film and $\mathrm{CO}_{2}$ was passed through the photoelectrocatalyst. Sasirekha et al. [80] reported the photoreduction of $\mathrm{CO}_{2}$ in water to produce methanol over Ru-doped $\mathrm{TiO}_{2}$ on $\mathrm{SiO}_{2}$. It was irradiated with a $1000 \mathrm{~W}$ high pressure mercury vapour lamp with a peak light intensity at $365 \mathrm{~nm}$ illumination. The ratio between $\mathrm{Ru}$ doping and $\mathrm{TiO}_{2}$ was found to have an effect on the efficiency of the reaction. Enhancements of efficiency were achieved when $0.5 \%$ of $\mathrm{Ru}(200 \mu \mathrm{mol} / \mathrm{g}$ of methanol and methane from $\left.\mathrm{CO}_{2}\right)$ or $10 \%$ of $\mathrm{TiO}_{2}(250 \mu \mathrm{mol} / \mathrm{g}$ of methanol and methane from $\mathrm{CO}_{2}$ ) was loaded with $\mathrm{SiO}_{2}$. However, $\mathrm{Ru}-\mathrm{TiO}_{2} / \mathrm{SiO}_{2}$ had a lower activity than $\mathrm{TiO}_{2} / \mathrm{SiO}_{2}$. The increase in efficiency was attributed to the UV transparent property of silica such that there was no loss of effectiveness of the UV irradiation on $\mathrm{TiO}_{2}$, as was the case with bulk $\mathrm{TiO}_{2}[81]$.

$\mathrm{Xia}$ et al. [82] reported the use of multiwalled carbon nanotubes blended with $\mathrm{TiO}_{2}$ for $\mathrm{CO}_{2}$ and water reduction. The selectivity of the product depended on the method used in material preparation: formic acid was obtained from hydrothermal synthesis and ethanol was produced from sol-gel synthesis. A recent research in the photocatalytic reduction of gas phase $\mathrm{CO}_{2}$ by solar radiation was reported by Varghese and co-workers [83] using $\mathrm{TiO}_{2}$ nanotube arrays with copper and Pt nanoparticles. Water vapour saturated carbon dioxide was reduced to methane and other hydrocarbons without an external bias. Various hydrocarbons were obtained at a production rate of $160 \mu \mathrm{l} /(\mathrm{g} \cdot \mathrm{h})$ under AM 1.5 sunlight with loaded $\mathrm{Cu}$ and $\mathrm{Pt}$.

$\mathrm{Wu}$ [84] reported methanol production $(4.12 \mu \mathrm{mol} /(\mathrm{g} \cdot \mathrm{h}))$ when a $1.0 \mathrm{wt} \% \mathrm{Ag} / \mathrm{TiO}_{2}$ photocatalyst (coated around an optical fibre) was irradiated under a light intensity of 10 $\mathrm{W} / \mathrm{cm}^{2}$ in a specially designed reactor. An in situ FT-IR (Fourier transform infrared spectroscopy) study was carried out to investigate the mechanism of $\mathrm{CO}_{2}$ reduction. The study proposed the reduction of $\mathrm{CO}_{2}$ under UV irradiation occurred by a multistep mechanism, starting from the adsorption of linear $\mathrm{CO}_{2}$. An electron and one hydrogen atom were added to yield products in the formate HCOO. Dioxymethylene $\left(\mathrm{H}_{2} \mathrm{COO}\right)$ was then produced by adding another hydrogen atom. Dioxymethylene migrated to the oxygen vacancy on the $\mathrm{TiO}_{2}$ site and accepted one electron and one oxygen atom was detached to form formaldehyde $\left(\mathrm{H}_{2} \mathrm{CO}\right)$. Following this, methoxy $\left(\mathrm{CH}_{3} \mathrm{O}\right)$ was formed from accepting another hydrogen atom. Finally, the methoxy reacted with water to give methanol [84]. In another report, $\mathrm{NiO}$ loaded $\mathrm{InTaO}_{4}$ was examined in an optical fibre reactor. Methanol was yielded with production rate $11.3 \mu \mathrm{mol} /(\mathrm{g} \cdot \mathrm{h})$ under concentrated sunlight and $11.1 \mu \mathrm{mol} /(\mathrm{g} \cdot \mathrm{h})$ under 100 W halogen lamp [85]. 
Beside the developments made on $\mathrm{TiO}_{2}$, several reports have been published on new photocatalytic materials for $\mathrm{CO}_{2}$ reduction. After $\mathrm{ZrO}_{2}$ was reported to be photocatalytically active for water splitting, Sayama and Arakawa [31] also found that $\mathrm{ZrO}_{2}$ can reduce $\mathrm{CO}_{2}$. They investigated the phenomena using a $1 \% \mathrm{Cu}$ cocatalyst loaded $-\mathrm{ZrO}_{2}$ as the photocatalyst in a $\mathrm{NaHCO}_{3}$ solution (to provide the $\mathrm{CO}_{2}$ ) under $\mathrm{Hg}$ lamp illumination. The reaction produced 19.5 $\mathrm{mmol} / \mathrm{h}$ hydrogen, $10.8 \mathrm{mmol} / \mathrm{h}$ oxygen, and $2.5 \mathrm{mmol} / \mathrm{h}$ carbon monoxide. Lo et al. [86] have also investigated the use of $\mathrm{ZrO}_{2}$ and $\mathrm{P} 25$ powder for $\mathrm{CO}_{2}$ photoconversion using $\mathrm{CO}_{2}$ mixed with $\mathrm{H}_{2}$ and water under UV illumination. Carbon monoxide was produced as a sole product with $\mathrm{ZrO}_{2}$, while with $\mathrm{P} 25$, methane, carbon monoxide, and ethene were obtained. Halmann et al. [76] examined $\mathrm{CO}_{2}$ photoreduction by $\mathrm{SrTiO}_{3}$ under sunlight in aqueous solution with $\mathrm{CO}_{2}$ bubbling. Formic acid, formaldehyde, and methanol were produced as products. Matsumoto et al. [87] reported a p-type $\mathrm{CaFe}_{2} \mathrm{O}_{4}$ in sodium hydroxide solution under $\mathrm{Hg}$ lamp to convert $\mathrm{CO}_{2}$, and obtained methanol and formaldehyde as the main product. Yan et al. [88] very recently reduced $\mathrm{CO}_{2}$ by the UV driven material $\mathrm{ZnGa}_{2} \mathrm{O}_{4}$ in gaseous $\mathrm{CO}_{2}$ with a small amount of water under a $300 \mathrm{~W}$ Xe lamp. Methane was detected under light irradiation. The production rate increased when mesoporous $\mathrm{ZnGa}_{2} \mathrm{O}_{4}$ was used instead of the bulk material. The methane production rate $(4.8 \mu \mathrm{mol} /(\mathrm{g} \cdot \mathrm{h}))$ increased 10 fold when the catalyst was loaded with $1 \mathrm{wt} \% \mathrm{RuO}_{2}$ as co-catalyst on mesoporous $\mathrm{ZnGa}_{2} \mathrm{O}_{4}$. Lately, $\mathrm{ZnGa}_{2} \mathrm{O}_{4}$ nanoribbon was also synthesized, which exhibited an even higher methane production rate under the same conditions. Methane production rate reached $25 \mu \mathrm{mol} /(\mathrm{g} \cdot \mathrm{h})$ when $1 \% \mathrm{RuO}_{2}$ and $1 \%$ Pt were loaded [89].

Researchers have shown that increasing the dispersion of the photocatalysts had a positive effect on photoreactivity. Zeolite or silicate frameworks offer unique pore structures and ion exchange capacities; photocatalysts prepared within the zeolite cavity are highly dispersed. Anpo et al. [90] reported the reduction of $\mathrm{CO}_{2}$ with water vapor by titania anchored on zeolite at $328 \mathrm{~K}$ under $75 \mathrm{~W} \mathrm{Hg}$ lamp. It was found to have high selectivity for methanol formation. The addition of a Pt cocatalyst led to a shift in product selectivity: methane was obtained instead of methanol. In both reports, they emphasized that the $\mathrm{TiO}^{3+}-\mathrm{O}^{-}$charge transferred to the exited state of anchored titanium oxide played a significant role in determining photoactivity $[78,90]$. In another report, he reported Ti-containing porous $\mathrm{SiO}_{2}$ film reduced $\mathrm{CO}_{2}$ with water vapor gave $\mathrm{CH}_{4}$ and $\mathrm{CH}_{3} \mathrm{OH}$ with the quantum yield of $0.28 \%$ under $\mathrm{Hg}$ lamp radiation. They proposed a ligand-to-metal charge-transfer excitation of isolated $\mathrm{Ti}$ centers of framework-substituted micro or mesoporous silicates by UV light, which can be used to reduce $\mathrm{CO}_{2}$ with
$\mathrm{H}_{2} \mathrm{O}$ at substantially better efficiency than the dense phase $\mathrm{TiO}_{2}$ particles [91]. Ulagappam and Frei [92] reduced gaseous $\mathrm{CO}_{2}$ by Ti silicate molecular sieves under $266 \mathrm{~nm} \mathrm{UV}$ radiation to obtain formic acid, acetic acid, and CO. FT-IR studies of the reaction showed that formation of $\mathrm{CO}$ was produced by the photolysis of formic acid, and acetic acid were synthesised from the Tischenko reaction of formaldehyde [92]. Lin and co-workers [93] studied the reduction of $\mathrm{CO}_{2}$ and water vapour/ $\mathrm{D}_{2} \mathrm{O}$ vapour by TiMCM-41 molecular sieve under laser light. Carbon monoxide was the only product in the reaction, and the production rate was directly proportional to the power of the laser. FT-IR data showed that formation of $\mathrm{CO}$ was due to the double electron transfer of $\mathrm{CO}_{2}$. In Lin and Frei's work [94], $\mathrm{CO}_{2}$ was reduced by $\mathrm{ZrCu}(\mathrm{I})-\mathrm{MCM}-41$ silicate sieve under $355 \mathrm{~nm}$ UV irradiation to give $\mathrm{CO}$ and $\mathrm{O}_{2}$.

While several new oxide photocatalysts were being developed, the process of photoreduction by metallic complex catalysts, such as ruthenium complexes, has also drawn equal interest. Takeda et al. [95] reported the reduction of $\mathrm{CO}_{2}$ by a rhenium complex in DMF solution to give CO. Lehn and Ziessel [96] investigated the use of $\mathrm{Ru}\left(2,2^{\prime} \text {-bipyridine }\right)_{3}{ }^{2+}$ cobalt (II) chloride in a mixture of $\mathrm{CH}_{3} \mathrm{CN} / \mathrm{H}_{2} \mathrm{O} / \mathrm{N}\left(\mathrm{CH}_{2} \mathrm{CH}_{3}\right)_{3}$ to reduce $\mathrm{CO}_{2}$ under visible light illumination. Craig et al. [97] reported $\mathrm{CO}_{2}$ can be reduced by $\mathrm{Ru}(\mathrm{bpy})^{\prime^{+}}$with a Ni complex cocatalyst in an adsorbate buffered solution to give CO. There is serious concern of cost and stability of these noble metal-based complex photocatalysts in aqueous solution. Fujita [98] has summarised the early developments in this field using different metal complexes.

In the majority of these reports, no concurrent $\mathrm{O}_{2}$ production was reported and most $\mathrm{CO}_{2}$ reduction reactions were achieved in an electrochemical cell requiring UV illumination and/or an electrical bias. The maximum conversion of $\mathrm{CO}_{2}$ was at the micromole level per hour. The efficiency of this process is therefore extremely low at this stage and the details of the mechanism of this reaction have yet to be clarified, which lags considerably behind solar hydrogen research. However the potential of the field is huge: this technology can provide the best solution to decrease $\mathrm{CO}_{2}$ emission and the desired products are compatible with present fuel transportation and storage systems, which thus can be used directly by users. For future development, more efficient materials and structure need to be found. Given the importance of the mechanism underlying $\mathrm{CO}_{2}$ photoconversion, it has hardly been addressed and should be paid more attention in the future. For more on $\mathrm{CO}_{2}$ conversion, the very recent report of Roy et al. [13] is recommended, which discussed the conversion of $\mathrm{CO}_{2}$ with different strategies including biomass, thermochemical, electrochemical and photochemical conversions. Usubharatana et al. [14] have 
also summarized the progress of photocatalyst development, concentrating on the design of the photoreactor, effect of $\mathrm{CO}_{2}$ concentration and reaction temperature.

\section{Key factors in determining photocatalyst activity}

\subsection{Particle size of photocatalyst}

The particle size of a photocatalyst has a direct effect on the photocatalytic reactivity. The change in reactivity may be caused by several factors as follows. (1) Total surface area per volume of the photocatalyst increases. It is expected that the surface area has a direct effect on the photocatalytic activity. The increase in surface area provides more reaction sites. (2) The particle size has a significant effect on initial charge carrier transportation and separation and thus on the rate of electron-hole recombination. For example, in the study on $\mathrm{NaNbO}_{3}$ samples, an increase from 1.7 $\mathrm{m}^{2} / \mathrm{g}$ to $38 \mathrm{~m}^{2} / \mathrm{g}$ in surface area by changing the synthesis method led to a tripling in $\mathrm{O}_{2}$ evolution rate and the $\mathrm{H}_{2}$ production rate increased six fold [99]. (3) Several theoretical results have been published showing that the particle size of the semiconductor nanoparticle has a direct effect on the semiconductor bandgap [100-104]. A decrease in particle size resulted in an enlargement of the bandgap of the photocatalyst, consequently both oxidising and reduction power became stronger [104].

\subsection{Choice of cocatalyst}

Cocatalysts have been shown to be very important and to some extent crucial in determining the activity of a system. For photochemical water splitting, cocatalysts such as $\mathrm{NiO}$, $\mathrm{RuO}_{2}, \mathrm{Pt}$, and $\mathrm{Rh}_{2-x} \mathrm{Cr}_{x} \mathrm{O}_{3}$ are often employed. $\mathrm{NiO}$ has been very widely used to achieve stoichiometric hydrogen and oxygen production from water [28]. The effects of cocatalysts are clearly shown on the two most active materials for photocatalytic water splitting under visible light. The $\mathrm{NiO} / \mathrm{Ni}$ shell/core structure is the key factor in the activity of $\mathrm{In}_{0.9} \mathrm{Ni}_{0.1} \mathrm{TaO}_{4}$ [57], whilst $\mathrm{Ga}_{0.88} \mathrm{~N}_{0.88} \mathrm{Zn}_{0.12} \mathrm{O}_{0.12}$ does not show any activity for water splitting in the absence of $\mathrm{Rh}_{2-x} \mathrm{Cr}_{x} \mathrm{O}_{3}$. Currently the exact mechanisms of enhancement of activity are not known for most cocatalysts, which complicates the choice of the appropriate material. The water splitting performance of $\mathrm{Zn}_{2} \mathrm{GeO}_{4}$ was found to increase by mounting the system with $\mathrm{Pt}$ and $\mathrm{RuO}_{2}$. The photocatalytic activity of $\mathrm{Pt}-\mathrm{RuO}_{2} / \mathrm{Zn}_{2} \mathrm{GeO}_{4}$ markedly increased from 4.0 to $53.4 \mu \mathrm{mol} / \mathrm{h}$ for hydrogen production and 2.0 to 26.0 $\mu \mathrm{mol} / \mathrm{h}$ for oxygen production [105].

Liu et al. [67] reported $\mathrm{Y}_{2} \mathrm{Ta}_{2} \mathrm{O}_{5} \mathrm{~N}_{2}$ photoactivity was promoted by the deposition of metal $\mathrm{Pt}$ and $\mathrm{Ru}$, and the maxi- mum hydrogen evolution rate $(833 \mu \mathrm{mol} /(\mathrm{h} \cdot \mathrm{g})$ was found with $0.15 \mathrm{wt} \% \mathrm{Pt}$ and $0.25 \mathrm{wt} \% \mathrm{Ru}$ coated on $\mathrm{Y}_{2} \mathrm{Ta}_{2} \mathrm{O}_{5} \mathrm{~N}_{2}$, which was 22 times more than that for $0.15 \mathrm{wt} \%$ $\mathrm{Pt} / \mathrm{Y}_{2} \mathrm{Ta}_{2} \mathrm{O}_{5} \mathrm{~N}_{2}$. Recently, Maeda et al. [106] reported for the first time the possibility of enhancing overall water splitting by the addition of both core/shell-structured $\mathrm{Rh} / \mathrm{Cr}_{2} \mathrm{O}_{3}$ and $\mathrm{Mn}_{3} \mathrm{O}_{4}$ nanoparticles as $\mathrm{H}_{2}$ and $\mathrm{O}_{2}$ evolution promoters onto the same photocatalyst.

For $\mathrm{CO}_{2}$ conversion, there are also a few examples that showed the addition of a cocatalyst led to an increase in catalytic performance and can change the end product of the reaction. The photocatalytic performance of $\mathrm{TiO}_{2}$ was improved by the addition of a $\mathrm{Cu}$ cocatalyst [107]. Cook and co-workers [108] reported the reduction of $\mathrm{CO}_{2}$ by $\mathrm{SiC}$ to different hydrocarbons $\left(\mathrm{CH}_{4}, \mathrm{C}_{2} \mathrm{H}_{4}\right.$, and $\left.\mathrm{C}_{2} \mathrm{H}_{6}\right)$ as a function of electrolyte $\mathrm{pH}$. SiC performance was enhanced by loading a $\mathrm{Cu}$ cocatalyst, showing that $\mathrm{Cu}$ particles enhanced the reduction of $\mathrm{CO}_{2}$. In another experiment, a gaseous water and $\mathrm{CO}_{2}$ mixture was reduced by $\mathrm{TiO}_{2}-\mathrm{SiO}_{2}$-acetylacetone (ACAC) under UVA radiation. Methane was obtained from pure $\mathrm{TiO}_{2}-\mathrm{SiO}_{2}-\mathrm{ACAC}$, whereas in the presence of $0.5 \mathrm{wt} \%$ $\mathrm{Cu}$ and $0.5 \mathrm{wt} \% \mathrm{Fe}$ cocatalysts, both methane and ethylene were detected [84].

\subsection{Other factors}

The crystal structure and morphology of the photocatalyst also play an important role in influencing the photocatalytic performance. Ye et al. [44-46] found that $\mathrm{SrSnO}_{3}$ prepared by two different methods showed significantly different activity: $\mathrm{SrSnO}_{3}$ consists of sphere-like particles when synthesized by a solid state reaction while the other sample was a nano-rod structure when prepared by hydrothermal synthesis. Both materials had a similar optical absorption and surface area, but the photocatalytic activity was found to be 10 times higher with the nano-rod structure.

A similar phenomenon was also observed on $\mathrm{TiO}_{2}$, and a correlation between the surface phases of $\mathrm{TiO}_{2}$ and its photocatalytic performance was investigated by Zhang et al. [109]. The photocatalytic activity of $\mathrm{TiO}_{2}$ was found to increase dramatically when anatase $\mathrm{TiO}_{2}$ particles were deposited on the surface of a rutile $\mathrm{TiO}_{2}$ bulk. The phenomenon was suggested to be caused by a surface-phase junction to facilitate the charge separation, which in turn increased the photogenerated hole-electron lifetime. This led to the increase in photocatalytic activity.

The effect of $\mathrm{La}$ doping of $\mathrm{NaTaO}_{3}$ was reviewed and the presence of the dopant led to a nanostructuring effect that was proposed to be a key factor in a large enhancement in photocatalytic activity $[36,110]$. $\mathrm{LiTaO}_{3}$ and $\mathrm{KTaO}_{3}$ consist of corner-shared $\mathrm{TaO}_{6}$ octahedra. Their ability at splitting water was investigated and it was found the closer the bond 
angle of Ta-O-Ta was to $180^{\circ}$, the better the charge separation and the smaller the band gap. Upon changing the alkali metal, $\mathrm{LiTaO}_{3}, \mathrm{NaTaO}_{3}, \mathrm{KTaO}_{3}$ have Ta-O-Ta angles of $143^{\circ}, 163^{\circ}$, and $180^{\circ}$, respectively. This was reported to enhance electron-hole migration through the crystal $\left(\mathrm{LiTaO}_{3}<\right.$ $\mathrm{NaTaO}_{3}<\mathrm{KTaO}_{3}$ ) which had an effect on the photocatalytic activity, as shown in Table 1 [33-35].

Table 1 Photoactivity of different alkali metal tantalates for water splitting [33-35]

\begin{tabular}{lccc}
\hline \multirow{2}{*}{ Catalyst } & Band gap $(\mathrm{eV})$ & \multicolumn{2}{c}{ Activity $(\mathrm{mol} / \mathrm{h})$} \\
\cline { 3 - 4 } & 4.7 & $\mathrm{H}_{2}$ & $\mathrm{O}_{2}$ \\
\hline $\mathrm{LiTaO}_{3}$ & 4.0 & 6 & 2 \\
$\mathrm{NaTaO}_{3}$ & 3.6 & 29 & 1 \\
$\mathrm{KTaO}_{3}$ & & 29 & 13 \\
\hline
\end{tabular}

The effects of the condition of stabilizers used on semiconductor materials for $\mathrm{CO}_{2}$ conversion have also been investigated. $\mathrm{Cd}\left(\mathrm{ClO}_{4}\right)_{2}$ and different types of polymers were mixed to prepared CdS. A different polymer used led to a different product. A negatively charged stabilizer favoured the photoreduction of $\mathrm{CO}_{2}$ to formate, while $\mathrm{CO}$ was more easily produced with a positively charged polymer under Xe lamp radiation $[104,111]$.

\section{Mechanism of photocatalytic synthesis}

An estimate states that the minimum requirement of $10 \%$ conversion efficiency is required for light driven photocatalytic hydrogen production to become commercially viable [112]. Currently, no reported material has met this requirement in prolonged periods of use.

The solar energy conversion efficiency is assumed to be below $1 \%$ in the above researches although the authors did not report the conversion efficiency but the quantum yield [71]. Knowing the mechanism of the photocatalytic process would help the development of new materials in this field. However, very little effort has been put into mechanistic research, with only a few reports on the fundamental mechanisms of water splitting and $\mathrm{CO}_{2}$ photoreduction being published.

As mentioned above, there are three basic processes in semiconductor photocatalysis. In addition to extending the absorption profile of materials to harvest a greater portion of the solar spectrum by narrowing the band width of the material, minimizing the loss of electrons and holes excited by photons is equally important. Fundamental researches have mainly focused on the charge carrier separation and transportation. It is believed that a faster charger carrier separation rate leads to an increase in charges lifetime. Transient absorption spectroscopy (TAS) is a powerful technique to monitor the dynamics and life time of charge carriers. It is an extension of absorption spectroscopy. The absorbance of charge carriers at a particular wavelength or range of wavelengths in a sample is measured as a function of time after excitation by a flash of light. The pulse of light for excitation is generated by a laser and the light for measuring the absorbance can be either a laser or a CW lamp equipped with a monochrometer.

The behaviour of charge carriers in $\mathrm{TiO}_{2}$ has been investigated by TAS measurement following initial UV laser excitation of $\mathrm{TiO}_{2}$ colloids and nanocrystalline $\mathrm{TiO}_{2}$ films. The initial trapping time and further relaxation time have been reported as occurring within $200 \mathrm{fs}$ and $500 \mathrm{ps}$, respectively [113]. Tang et al. and other groups reported the TAS of the trapped photoelectrons and holes in $\mathrm{nc}-\mathrm{TiO}_{2}$, with a maximum absorption of holes at $450 \mathrm{~nm}$ and electrons at $800 \mathrm{~nm}$ upward [114-116].

The electron-hole decay time has been reported to be in a range of different rates with changing particle size. It was found that complete electron hole recombination occurred in $10 \mathrm{~ns}$ in $2.1 \mathrm{~nm}$ diameter $\mathrm{TiO}_{2}$ whereas only $90 \%$ of the charge carriers recombined within $10 \mathrm{~ns}$ in $13.3 \mathrm{~nm}$ and $26.7 \mathrm{~nm} \mathrm{TiO}_{2}$ colloidal particle [117]. Several TAS studies have proposed the UV excitation intensity has an effect on the rate of recombination. Under light intensities that are close to solar radiation intensities, power law type decays beyond the microsecond timescale have been observed $[113,116,118]$. This fast electron-hole recombination was believed to be the main reason behind the lack of water splitting activity of nc- $\mathrm{TiO}_{2}$ without a cocatalyst or chemical scavenger. Tang et al. [116] reported that in the presence of a silver $\left(\mathrm{Ag}^{+}\right)$electron-scavenger, the reaction rate between $\mathrm{Ag}^{+}$and the electron was very fast, leaving holes to react with water to produce $\mathrm{O}_{2}$ (Fig. 3(1) and (4)). $\mathrm{O}_{2}$ production has been estimated to require an average hole lifetime of

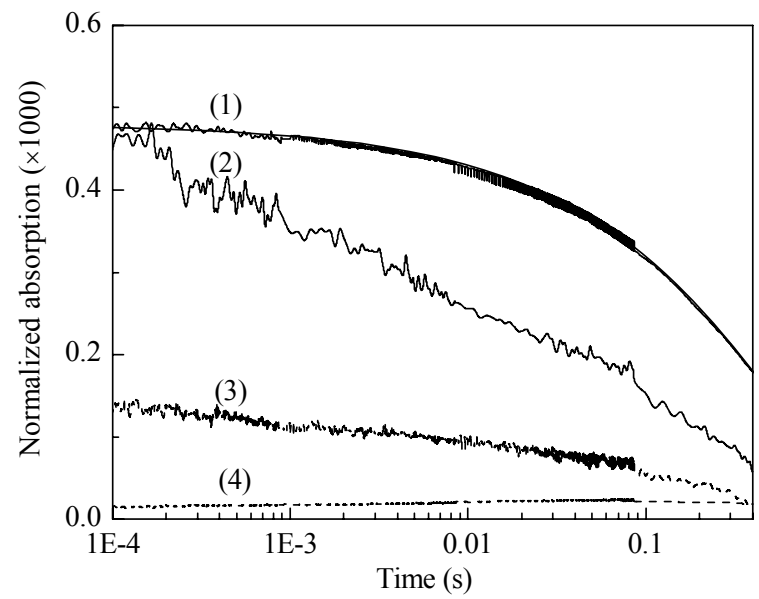

Fig. 3. Dynamics of holes (traces (1) and (2)) and electrons (traces (3 and (4)) in $\mathrm{TiO}_{2}$ film with $\mathrm{Ag}^{+}$(traces (1) and (4)) and Pt (traces (2) and (3)) as the electron scavengers after bandgap excitation with laser wavelength of $335 \mathrm{~nm}$. Figure reproduced from Ref. [116]. 
$\sim 0.2 \mathrm{~s}$ at a neutral $\mathrm{pH}$. The observed rate of decay of the holes on $\mathrm{nc}-\mathrm{TiO}_{2}$ consisted of several components as water oxidation is a multi-step reaction. It has been suggested that four holes are required to oxidize water to produce one oxygen molecule in artificial water splitting systems. Later, they experimentally observed and proved the 4-hole chemistry in artificial water splitting systems [116]. In Fig. 4, an nc- $\mathrm{TiO}_{2}$ water splitting process is summarized to illustrate the key reaction timescales, which was based on a range of TAS studies [116,117,119].

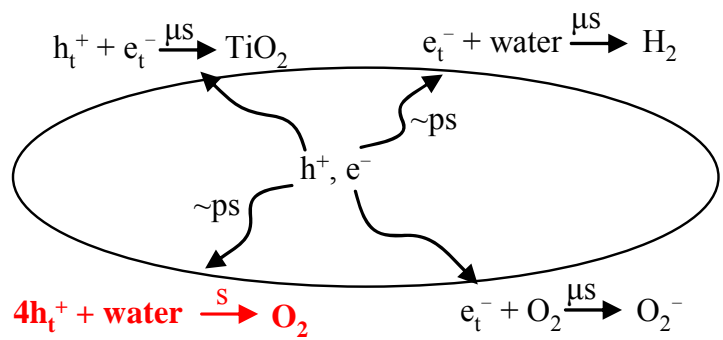

Fig. 4. Timescales of processes occurring on $\mathrm{nc}-\mathrm{TiO}_{2}$ following UV excitation. Figure reproduced from Ref. [116].

TAS measurements have also been studied on $\mathrm{TiO}_{2}$ co-doped with both $\mathrm{Sb}$ and $\mathrm{Cr}$ and several other materials closely related to nc- $\mathrm{TiO}_{2}$. These photocatalysts show oxygen production under visible light in the presence of $\mathrm{Ag}^{+}$as a scavenger. The maximum oxygen yield has been found to occur when $\mathrm{TiO}_{2}$ was doped with $\mathrm{Cr}$ and $\mathrm{Sb}$ in a 1:2 ratio, due to an increased charge carriers lifetime [120]. The electron hole dynamics on a range of materials including $\mathrm{TiO}_{2}$ hybrids and doped $\mathrm{TiO}_{2}$ samples has also been examined by the two groups of Majima's and Tang's. The previously mentioned alkali metal tantalates have been examined by Tachikawa et al. [121]. Besides restructuring the nano-morphology of $\mathrm{NaTaO}_{3}, \mathrm{La}$ doping leads to greatly reduced recombination in TAS measurements [122]. Tang et al. [123] recently reported the low efficiency of the nitrogen doped $\mathrm{TiO}_{2}$ was mainly due to the newly-generated trapped sites of electrons.

As discussed above, $\mathrm{CO}_{2}$ photoreduction has received much less attention than solar hydrogen production. Although the knowledge is known to be important for enhancing material efficiency, there are few studies on the mechanism of $\mathrm{CO}_{2}$ photoreduction. Nevertheless, the process of $\mathrm{CO}_{2}$ reduction shares an approximately similar mechanism with solar water splitting. Experiences gained from water splitting may also be applied to $\mathrm{CO}_{2}$ photoreduction.

\section{Conclusions}

Directly utilizing solar energy will provide future genera- tions with a sustainable power source and a clean environment. However, the storage of solar energy has been a major problem in the field. The ideal solution is to convert solar energy into readily transportable and highly energetic chemicals, e.g. hydrogen or hydrocarbon fuels. The benefits of photocatalytic water splitting or $\mathrm{CO}_{2}$ conversion will truly be realized when accompanied by an effective hydrogen/methanol fuel cell/engine to utilize the fuels and oxygen produced from a photocatalytic system to generate power and water, giving us a carbon free or carbon neutral cycle.

During the past 30 years, many efforts have been made towards the development of materials and systems to convert water to $\mathrm{O}_{2}$ and $\mathrm{H}_{2}$ together in a water splitting process, or to convert $\mathrm{CO}_{2}$ to hydrocarbon fuels. Unfortunately, to date there is no material or device that has the required conversion efficiency to make this technology economically and commercially viable. The key factors which have been reported including band positions of the conduction and valence bands, the choice of cocatalyst, the morphology and particle size, are aspects of the field which must be pursued. Fundamental research on exploring how electrons and holes move and react in each photocatalyst will give a better understanding of the factors that control photocatalytic activity. This has not been clearly identified and should be addressed systematically for an efficient photochemical process.

\section{Acknowledgments}

Funding from EPSRC on Solutions is gratefully acknowledged.

\section{References}

1 Hoffert M I, Caldeira K, Jain A K, Haites E F, Harvey L D D, Potter S D, Schlesinger M E, Schneider S H, Watts R G, Wigley T M L, Wuebbles D J. Nature, 1998, 395: 881

2 Lewis N S, Nocera D G. Proc Natl Acad Sci USA, 2006, 103: 15729

3 Energy Information Administration. Annual Energy Review 2008. Washington DC: U.S. Department of Energy, 2009

4 Barber J. Chem Soc Rev, 2009, 38: 185

5 Hansen J E. Environmental Research Letters, 2007, 2: 024002

6 Hansen J E, Sato M, Kharecha P, Beerling D, Berner R, Masson-Delmotte V, Pagani M, Raymo M, Royer D L, Zachos J C. The Open Atmospheric Science Journal, 2008, 2: 217

$7 \mathrm{Http} / / /$ fossil.energy.gov/sequestration/geologic/index.html, U.S. Department of Energy, 2010

8 Halbwachs M, Sabroux J C. Science, 2001, 292: 438

9 Chisti Y. Biotechnol Adv, 2007, 25: 294

10 Sharma Y C, Singh B, Upadhyay S N. Fuel, 2008, 87: 2355

11 Tang J W, Cowan A. In: Griesbeck A, Oelgemoeller M, Ghetti F, eds. CRC Handbook of Organic Photochemistry \& Photo- 
biology. 3rd Ed. London: CRC Press, 2012

12 Kudo A, Miseki Y. Chem Soc Rev, 2009, 38: 253

13 Roy S C, Varghese O K, Paulose M, Grimes C A. ACS Nano, 2010, 4: 1259

14 Usubharatana P, McMartin D, Veawab A, Tontiwachwuthikul P. Ind Eng Chem Res, 2006, 45: 2558

15 Centi G, Perathoner S. ChemSusChem, 2010, 3: 195

16 Fujishima A, Honda K. Nature, 1972, 238: 37

17 Yamaguti K, Sato S. J Chem Soc, Faraday Trans I, 1985, 81: 1237

18 Selli E, Chiarello G L, Quartarone E, Mustarelli P, Rossetti I, Forni L. Chem Commun, 2007: 5022

19 Duonghong D, Borgarello E, Gratzel M. J Am Chem Soc, 1981, 103: 4685

20 Sato S, White J M. Chem Phys Lett, 1980, 72: 83

$21 \mathrm{Fu}$ N, Wu Y, Jin Z, Lu G. Langmuir, 2010, 26: 447

22 Li Y X, Me Y Z, Peng S Q, Lu G X, Li S B. Chemosphere, 2006, 63: 1312

23 Domen K, Kudo A, Onishi T. J Catal, 1986, 102: 92

24 Domen K, Kudo A, Onishi T, Kosugi N, Kuroda H. J Phys Chem, 1986, 90: 292

25 Domen K, Kudo A, Shibata M, Tanaka A, Maruya K, Onishi T. Chem Commun, 1986: 1706

26 Domen K, Naito S, Onishi T, Tamaru K, Samo M. Chem Phys Lett, 1982, 92: 433

27 Domen K, Naito S, Onishi T, Tamaru K, Samo M. J Phys Chem, 1982, 86: 3657

28 Domen K, Naito S, Soma M, Onishi T, Tamaru K. Chem Commun, 1980: 543

29 Kim J, Hwang D W, Kim H G, Bae S W, Lee J S, Li W, Oh S H. Top Catal, 2005, 35: 295

30 Chang S M, Doong R A. J Phys Chem B, 2004, 108: 18098

31 Sayama K, Arakawa H. J Phys Chem, 1993, 97: 531

32 Jiang L, Wang Q Z, Li C L, Yuan J A, Shangguan W F. Int J Hydrogen Energy, 2010, 35: 7043

33 Sayama K, Arakawa H, Domen K. Catal Today, 1996, 28: 175 34 Kato H, Kudo A. Chem Phys Lett, 1998, 295: 487

35 Kato H, Kudo A. J Phys Chem B, 2001, 105: 4285

36 Kato H, Asakura K, Kudo A. J Am Chem Soc, 2003, 125: 3082

37 Mitsui C, Nishiguchi H, Fukamachi K, Ishihara T, Takita Y. Chem Lett, 1999, 1327

38 Ikeda S, Fubuki M, Takahara Y K, Matsumura M. Appl Catal A, 2006, 300: 186

39 Kudo A, Kato H, Nakagawa S. J Phys Chem B, 2000, 104: 571

40 Kato H, Kudo A. Chem Lett, 1999, 1207

41 Yoshino M, Kakihana M, Cho W S, Kato H, Kudo A. Chem Mater, 2002, 14: 3369

42 Sato J, Kobayashi H, Inoue Y. J Phys Chem B, 2003, 107: 7970

43 Sato J, Kobayashi H, Saito N, Nishiyama H, Inoue Y. J Photochem Photobiol A, 2003, 158: 139

44 Zhang W F, Tang J W, Ye J H. Chem Phys Lett, 2006, 418: 174

45 Zhang W F, Tang J W, Ye J H. J Mater Res, 2007, 22: 1859

46 Chen D, Ye J H. Chem Mater, 2007, 19: 4585
47 Sato J, Saito N, Nishiyama H, Inoue Y. J Photochem Photobiol A, 2002, 148: 85

48 Yanagida S, Azuma T, Sakurai H. Chem Lett, 1982: 1069

49 Reber J F, Meier K. J Phys Chem, 1984, 88: 5903

$50 \mathrm{Wu}$ M, Gu W Z, Li W Z, Zhu X W, Wang F D, Zhao S T. Sci Technol Catal, 1995, 92: 257

51 Kobayakawa K, Teranishi A, Tsurumaki T, Sato Y, Fujishima A. Electrochim Acta, 1992, 37: 465

52 Tang J W, Ye J H. J Mater Chem, 2005, 15: 4246

53 Tang J W, Zou Z G, Ye J H. J Phys Chem B, 2003, 107: 14265

54 Kudo A, Omori K, Kato H. J Am Chem Soc, 1999, 121: 11459

55 Kudo A, Ueda K, Kato H, Mikami I. Catal Lett, 1998, 53: 229

56 Yu J Q, Kudo A. Adv Funct Mater, 2006, 16: 2163

57 Zou Z G, Ye J H, Sayama K, Arakawa H. Nature, 2001, 414: 625

58 Mills A, Porter G. J Chem Soc, Faraday Trans I, 1982, 78: 3659

59 Darwent J R. J Chem Soc, Faraday Trans II, 1981, 77: 1703

60 Darwent J R, Porter G. Chem Commun, 1981: 145

61 Yan H J, Yang J H, Ma G J, Wu G P, Zong X, Lei Z B, Shi J Y, Li C. J Catal, 2009, 266: 165

62 Kalyanasundaram K, Borgarello E, Duonghong D, Gratzel M. Angew Chem, Int Ed, 1981, 20: 987

63 Hara M, Hitoki G, Takata T, Kondo J N, Kobayashi H, Domen K. Catal Today, 2003, 78: 555

64 Hara M, Nunoshige J, Takata T, Kondo J N, Domen K. Chem Commun, 2003: 3000

65 Takata T, Hitoki G, Kondo J N, Hara M, Kobayashi H, Domen K. Res Chem Intermed, 2007, 33: 13

66 Yamasita D, Takata T, Hara M, Kondo J N, Domen K. Solid State Ionics, 2004, 172: 591

67 Liu M Y, You W S, Lei Z B, Zhou G H, Yang J J, Wu G P, Ma G J, Luan G Y, Takata T, Hara M, Domen K, Li C. Chem Commun, 2004: 2192

68 Hitoki G, Takata T, Kondo J N, Hara M, Kobayashi H, Domen K. Electrochemistry, 2002, 70: 463

69 Maeda K, Takata T, Hara M, Saito N, Inoue Y, Kobayashi H, Domen K. J Am Chem Soc, 2005, 127: 8286

70 Maeda K, Teramura K, Domen K. J Catal, 2008, 254: 198

71 Maeda K, Teramura K, Lu D L, Takata T, Saito N, Inoue Y, Domen K. Nature, 2006, 440: 295

72 Osterloh F E. Chem Mater, 2008, 20: 35

73 Halmann M. Nature, 1978, 275: 115

74 Canfield D, Frese K W. J Electrochem Soc, 1983, 130: 1772

75 Yamashita H, Nishiguchi H, Kamada N, Anpo M, Teraoka Y, Hatano H, Ehara S, Kikui K, Palmisano L, Sclafani A, Schiavello M, Fox M A. Res Chem Intermed, 1994, 20: 815

76 Inoue T, Fujishima A, Konishi S, Honda K. Nature, 1979, 277: 429

77 Yahaya A H, Gondal M A, Hameed A. Chem Phys Lett, 2004, 400: 206

78 Anpo M, Chiba K. J Mol Catal, 1992, 74: 207

79 Ichikawa S, Doi R. Catal Today, 1996, 27: 271

80 Sasirekha N, Basha S J S, Shanthi K. Appl Catal B, 2006, 62: 169 
81 Matthews R W. J Catal, 1988, 113: 549

82 Xia X H, Jia Z H, Yu Y, Liang Y, Wang Z, Ma L L. Carbon, 2007, 45: 717

83 Varghese O K, Paulose M, LaTempa T J, Grimes C A. Nano Lett, 2009, 9: 731

84 Wu J C S. Catal Surveys Asia, 2009, 13: 30

85 Wang Z Y, Chou H C, Wu J C S, Tsai D P, Mul G. Appl Catal A, 2010, 380: 172

86 Lo C C, Hung C H, Yuan C S, Wu J F. Sol Energy Mater Sol Cells, 2007, 91: 1765

87 Matsumoto Y, Obata M, Hombo J. J Phys Chem, 1994, 98: 2950

88 Yan S C, Ouyang S X, Gao J, Yang M, Feng J Y, Fan X X, Wan L J, Li Z S, Ye J H, Zhou Y, Zou Z G. Angew Chem, Int Ed, 2010, 49: 6400

89 Liu Q, Zhou Y, Kou J H, Chen X Y, Tian Z P, Gao J, Yan S C, Zou Z G. J Am Chem Soc, 2010, 132: 14385

90 Anpo M, Yamashita H, Ichihashi Y, Fujii Y, Honda M. J Phys Chem B, 1997, 101: 2632

91 Ikeue K, Nozaki S, Ogawa M, Anpo M. Catal Lett, 2002, 80: 111

92 Ulagappan N, Frei H. J Phys Chem A, 2000, 104: 7834

93 Lin W Y, Han H X, Frei H. J Phys Chem B, 2004, 108: 18269

94 Lin W Y, Frei H. J Am Chem Soc, 2005, 127: 1610

95 Takeda H, Koike K, Inoue H, Ishitani O. J Am Chem Soc, 2008, 130: 2023

96 Lehn J M, Ziessel R. Proc Natl Acad Sci USA, 1982, 79: 701

97 Craig C A, Spreer L O, Otvos J W, Calvin M. J Phys Chem, 1990, 94: 7957

98 Fujita E. Coord Chem Rev, 1999, 185-186: 373

99 Li G Q, Kako T, Wang D F, Zou Z G, Ye J H. J Phys Chem Solids, 2008, 69: 2487

100 Brus L E. J Chem Phys, 1984, 80: 4403

101 Lippens P E, Lannoo M. Phys Rev B, 1989, 39: 10935

102 Wang Y, Suna A, Mahler W, Kasowski R. J Chem Phys, 1987, 87: 7315

103 Henglein A. Chem Rev, 1989, 89: 1861
104 Yoneyama H. Catal Today, 1997, 39: 169

105 Ma B J, Wen F Y, Jiang H F, Yang J H, Ying P L, Li C. Catal Lett, 2010, 134: 78

106 Maeda K, Xiong A K, Yoshinaga T, Ikeda T, Sakamoto N, Hisatomi T, Takashima M, Lu D L, Kanehara M, Setoyama T, Teranishi T, Domen K. Angew Chem, Int Ed, 2010, 49: 4096

107 Adachi K, Ohta K, Mizuno T. Solar Energy, 1994, 53: 187

108 Cook R L, Macduff R C, Sammells A F. J Electrochem Soc, 1988, 135: 3069

109 Zhang J, Xu Q, Feng Z, Li M, Li C. Angew Chem, Int Ed, 2008, 47: 1766

110 Kudo A, Kato H. Chem Phys Lett, 2000, 331: 373

111 Inoue H, Nakamura R, Yoneyama H. Chem Lett, 1994: 1227

112 Bard A J, Fox M A. Acc Chem Res, 1995, 28: 141

113 Tamaki Y, Furube A, Murai M, Hara K, Katoh R, Tachiya M. Phys Chem Chem Phys, 2007, 9: 1453

114 Yoshihara T, Katoh R, Furube A, Tamaki Y, Murai M, Hara K, Murata S, Arakawa H, Tachiya M. J Phys Chem B, 2004, 108: 3817

115 Bahnemann D, Henglein A, Lilie J, Spanhel L. J Phys Chem, 1984, 88: 709

116 Tang J W, Durrant J R, Klug D R. J Am Chem Soc, 2008, 130: 13885

117 Serpone N, Lawless D, Khairutdinov R. J Phys Chem, 1995, 99: 16646

118 Murai M, Tamaki Y, Furube A, Hara K, Katoh R. Catal Today, 2007, 120: 214

119 Yamakata A, Ishibashi T, Onishi H. J Phys Chem B, 2001, 105: 7258

120 Ikeda T, Nomoto T, Eda K, Mizutani Y, Kato H, Kudo A, Onishi H. J Phys Chem C, 2008, 112: 1167

121 Tachikawa T, Fujitsuka M, Majima T. J Phys Chem C, 2007, 111: 5259

122 Yamakata A, Ishibashi T, Kato H, Kudo A, Onishi H. J Phys Chem B, 2003, 107: 14383

123 Tang J W, Cowan A, Durrant J R, Klug D R. J Phys Chem C, 2011, 115: 3143 